\title{
Cross pinning versus lateral pinning in type III supracondylar fracture: a retrospective analysis
}

\author{
Rajesh Govindasamy ${ }^{1 *}$, Ramkumar Gnanasundaram², Saravanan Kasirajan ${ }^{1}$, \\ Fawas Thonikadavath ${ }^{1}$, Rajeev K. Tiwari ${ }^{1}$
}

\author{
${ }^{1}$ Department of Orthopaedics, Vinayaka Missions medical college (V.M.M.C), Karaikal, Puducherry, India \\ ${ }^{2}$ Department of orthopaedics, Saveetha medical college, Chennai, India
}

Received: 22 July 2016

Accepted: 26 July 2016

\section{*Correspondence:}

Dr. Rajesh Govindasamy,

E-mail: drgrortho@yahoo.com

Copyright: (c) the author(s), publisher and licensee Medip Academy. This is an open-access article distributed under the terms of the Creative Commons Attribution Non-Commercial License, which permits unrestricted non-commercial use, distribution, and reproduction in any medium, provided the original work is properly cited.

\begin{abstract}
Background: The commonly accepted treatment of type III supracondylar fractures of humerus in children is closed reduction percutaneous pinning (CRPP). There is a long debate over stability and complications associated with cross and lateral pinning. The present study compares the functional outcome and complications of both pinning techniques.

Methods: A retrospective analysis of results with regard to ulnar nerve injury, carrying angle and range of movements was made in 27 children with lateral pinning and 28 children with crossed pinning was done in our institution. Functional outcome was graded according to Flynn's criteria and loss of reduction by Skagg's criteria.

Results: There was no statistically significant difference with regard to functional outcome and loss of reduction between the two groups. Iatrogenic ulnar nerve injury (IUNI) occurred in three cases (11\%) after crossed pinning in which two had significant palsy, which recovered by three months and the other had only transient paraesthesia.

Conclusions: Lateral pinning technique is reliably safe method in terms of stability as it avoids IUNI, we recommend it.
\end{abstract}

Keywords: Supracondylar fracture, Humerus, Crossed pinning, Lateral, Ulnar nerve, Carrying angle

\section{INTRODUCTION}

Supracondylar fracture of humerus in children is one of the most common fractures seen in the first decade of life. The modified Gartland system is most often used for classification of supracondylar humeral fractures in children (Table 1). ${ }^{1}$

Type III injuries are completely displaced with both cortices fractured. Wilkins subdivided Type III injuries according to the coronal plane displacement of the distal fragment into Posteromedial or Posterolateral injuries. ${ }^{2}$ This modification was clinically helpful in identifying complications from injury in problems with treatment.
The high incidence of residual deformity and the potential for neurovascular complications makes supracondylar humerus fractures a serious injury.

Table 1: Modified gartland classification of supracondylar fractures.

\begin{tabular}{|ll|}
\hline Type I & Undisplaced \\
\hline Type II & Hinged posteriorly \\
\hline Type III & Displaced \\
\hline Type IV & Displaces into extension \& flexion \\
\hline
\end{tabular}

The non-operative management of type III supracondylar fractures of humerus including Dunlop skin traction, 
skeletal traction and cast application has historically been associated with a greater incidence of failure to obtain and maintain the fracture reduction and have higher complication rates. ${ }^{3-6}$

The gold standard treatment for displaced Supracondylar fractures is closed reduction percutaneous pinning (CRPP). The debate persists in optimal pin configuration (Figure 1). Though crossed pinning provides increased biomechanical stability, it simultaneously carries the risk of iatrogenic ulnar nerve injury IUNI $(5 \%)$ due to medial pin placement. ${ }^{7}$

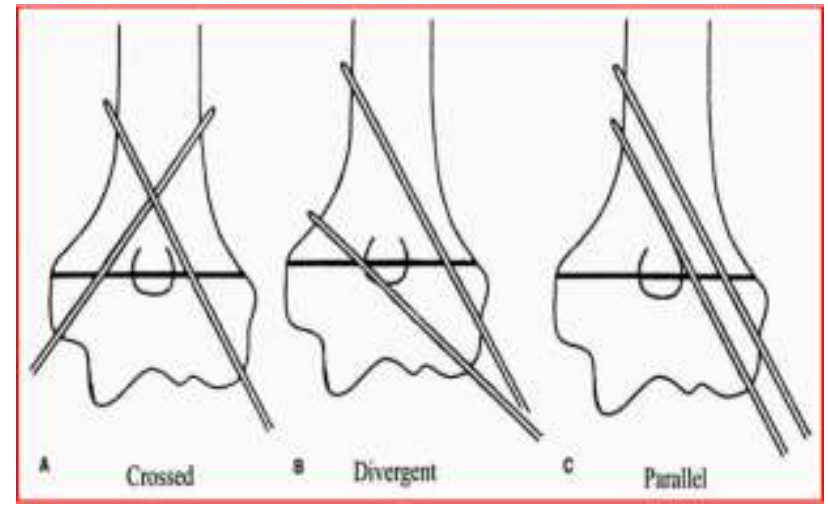

Figure 1: Criss-cross pinning versus lateral pinning.

Studies has shown lateral pinning done with proper technique provides same stability and avoids IUNI. ${ }^{7}$ The stability is increased by maximal separation of the pin at the fracture site and also where they cross the fracture site (Figure 2). ${ }^{7}$
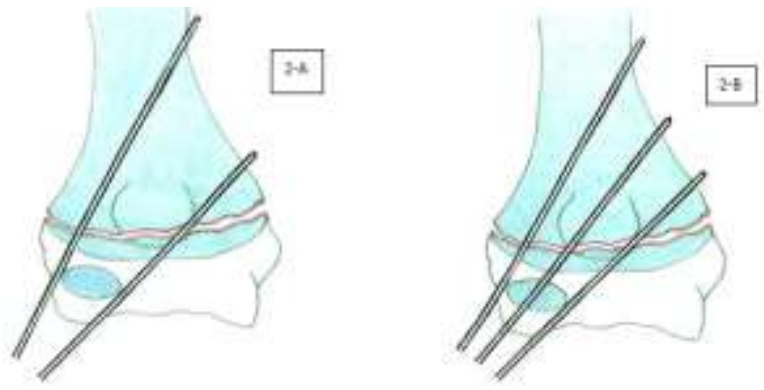

Figure 2: A and B-Correct positioning of lateral-entry pins.

The present study is to compare whether lateral pin construct, if placed properly, can provide the same stability like cross pinning, at the same time avoiding the possibility of IUNI.

\section{METHODS}

A retrospective analysis in 27 children treated with lateral pinning and 28 children with cross pinning between June 2013 to June 2015 was done. There were 16 boys and 11 girls treated with lateral pinning. In cross pinning group, there were 17 boys and 11 girls. In both the groups there were no children with any preoperative neurological deficits. Left side was predominant in both sexes. We had an inclusion and exclusion criteria.

\section{Inclusion criteria}

All type III supracondylar fractures of humerus of either side in either sex, in children between the age group of 212 years.

\section{Exclusion criteria}

a) Flexion type, b) Previous fractures in same limb, c) Type I and II fractures, d) Fracture requiring open reduction, e) With vascular injury, f) Any child with preoperative nerve injuries.

Immediately after the patients arrival to the hospital a detailed clinical examination including a thorough neurovascular assessment was carried out. Standard antero-posterior and lateral radiographs of the involved elbow were taken and the fracture type was noted. The cases were treated on an emergency basis with closed reduction and percutaneous pinning, under the guidance of C-arm image intensifier after informed written consent.

\section{Surgical technique}

General anaesthesia was employed for all cases. The patient was positioned supine on the operating table with affected limb being placed on a side table. Under the guidance of a sterile draped C-arm image intensifier, a step-wise closed manipulation was performed. Assessment of reduction was done clinically by assessing the carrying angle and radiologically by taking anteroposterior, lateral and Jones views.

Maintenance of reduction was achieved by passing two crossed K-wires from both the medial and lateral epicondyles or by passing two K-wires from the lateral condyle in parallel or crossed fashion. When crossed pinning was employed, the lateral pin was inserted first so that, the medial pin can be placed with the elbow in less flexion to avoid ulnar nerve injury.

The choice of crossed or lateral pin fixation was made according to the operating surgeon's personal preference. Severe edema and reductions which needed hyperflexion of elbow were fixed with lateral pinning where crossed pinning had a significant risk of IUNI. Once the pins were in place, the elbow was extended and the adequacy of reduction was assessed in both planes.

After leaving about $1 \mathrm{~cm}$ of the pins outside the skin, pins were cut off and bent and a well-padded posterior above elbow slab was applied with elbow flexed to 90 degrees or less as tolerated. Immediately in the postoperative period, the neurovascular status of the limb was assessed. 
Limb was immobilized in posterior slab with elbow in 60-80 degree of flexion depending upon the swelling and neurovascular status. Patients were reassessed for their neurovascular status and also for any Iatrogenic nerve injuries and were all discharged within 48 hours of surgery.

Patients were called after one week for check $\mathrm{X}$ ray for any displacement and pin site infection, then after 4 weeks for removal of slab, check $\mathrm{X}$ ray and removal of $\mathrm{K}$ wires after union followed by physiotherapy for elbow. Active elbow exercises were started from fourth week as tolerated by the child. Passive motion and forceful manipulation were avoided. Follow-up was done regularly at six weeks, three months and end of six months. At the end of six months follow up, the clinical outcome was measured by Flynn's criteria \& loss of reduction by Skagg's criteria (Table $2 \&$ Table 3). ${ }^{8,9}$

Table 2: Flynn et al.criteria for grading. ${ }^{8}$

\begin{tabular}{|llll|}
\hline \multirow{2}{*}{ Results } & Rating & $\begin{array}{l}\text { Cosmetic } \\
\text { factor: } \\
\text { carrying } \\
\text { angle loss } \\
\text { (degree) }\end{array}$ & $\begin{array}{l}\text { Functional } \\
\text { factor: } \\
\text { motion loss } \\
\text { (degrees) }\end{array}$ \\
\hline \multirow{3}{*}{ Satisfactory } & Excellent & $0-5$ & $0-5$ \\
\cline { 2 - 4 } & Good & $5-10$ & $5-10$ \\
\cline { 2 - 4 } & Fair & $10-15$ & $10-15$ \\
\hline Unsatisfactory & Poor & $>15$ & $>15$ \\
\hline
\end{tabular}

Table 3: Skaggs et al criteria for grading loss of reduction.'

\begin{tabular}{|ll|}
\hline $\begin{array}{l}\text { Change in Baumann angle } \\
\text { (in degrees) }\end{array}$ & $\begin{array}{l}\text { Loss of reduction } \\
\text { grading }\end{array}$ \\
\hline$<6$ & None \\
\hline $6-12$ & Mild \\
\hline$>12$ & Major \\
\hline
\end{tabular}

During the follow up period, pain, restriction of motion and satisfaction with appearance of elbow was assessed. Carrying angle and the range of flexion and extension of both the injuries and the normal elbow was measured with a goniometer and recorded. A neurological examination was performed to note recovery in case of neural deficit being noted previously. Statistical analysis was done by Chi-square test, T test and Fischer's exact test.

\section{RESULTS}

The peak incidence was in 5-8 years age group with an average age of 6.75 years. In our study, incidence in male children was $60 \%$ and $40 \%$ in females. The common mechanism of injury in our series was fall on an outstretched hand $(80 \%)$. In our study, there was $65 \%$ incidence of posteromedial displacements and $35 \%$ postero-lateral displacement. Ipsilateral associated injuries were present in 6 cases $(11 \%)$. The injuries were three distal radius fractures, two isolated fracture of ulna and one with fifth metacarpal fracture.

The average hospital stay for a patient in our study was 3 days with a range of 1 to 7 days. The minimum duration of six months of follow up in our study was adequate to assess fracture union, malalignment, range of motion and recovery from nerve injuries. The follow up ranges from six months to eighteen months.

The functional \& cosmetic outcome was measured using Flynn's criteria, 8 in lateral pinning twenty children (74\%) had excellent grading (Figure 3) and seven children $(26 \%)$ had good grading in view of loss of carrying angle. In cross pinning, twenty two children (78\%) had excellent grading (Figure 4) and six children (22\%) had good grading.
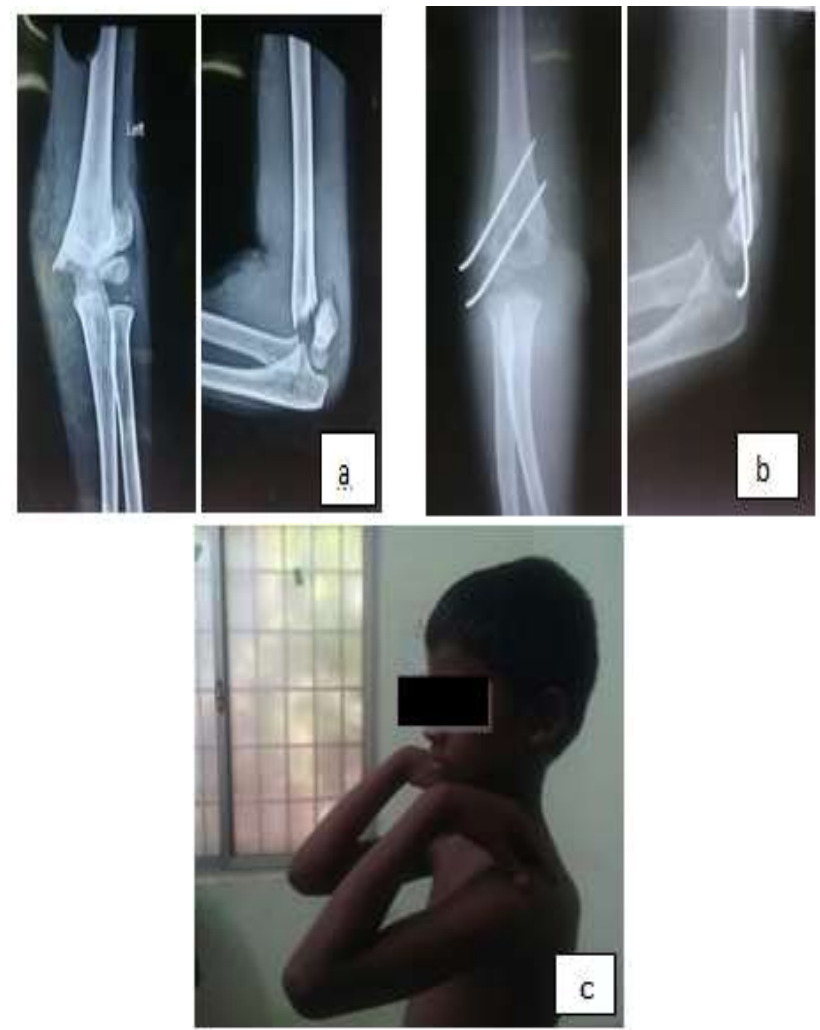

Figure 3: a) Pre operative b) post operative radiograph with a two lateral pin fixation c) six month follow up clinical picture with excellent outcome according to flynn's criteria.

In both techniques, there were excellent functional results with less than 5 degree loss of range of motion in most children (96\%). Only two (4\%) had good results. None had fair or poor results. The average change in carrying angle in cases treated by crossed pinning was 2.5 degrees with range of 0-7 degrees; five children had loss of carrying angle between 5-7 degree in this group. The difference in the carrying angle between the two groups was not statistically significant $(\mathrm{p}=0.356)$. However, 
there was no cubitus varus deformity in either group in our study and children were satisfied with the cosmetic appearance of their elbows. The difference in functional outcome between two groups was not statistically significant $\left(\mathrm{x}^{2}=0.837, \mathrm{p}=0.386\right)$. All fractures united well.
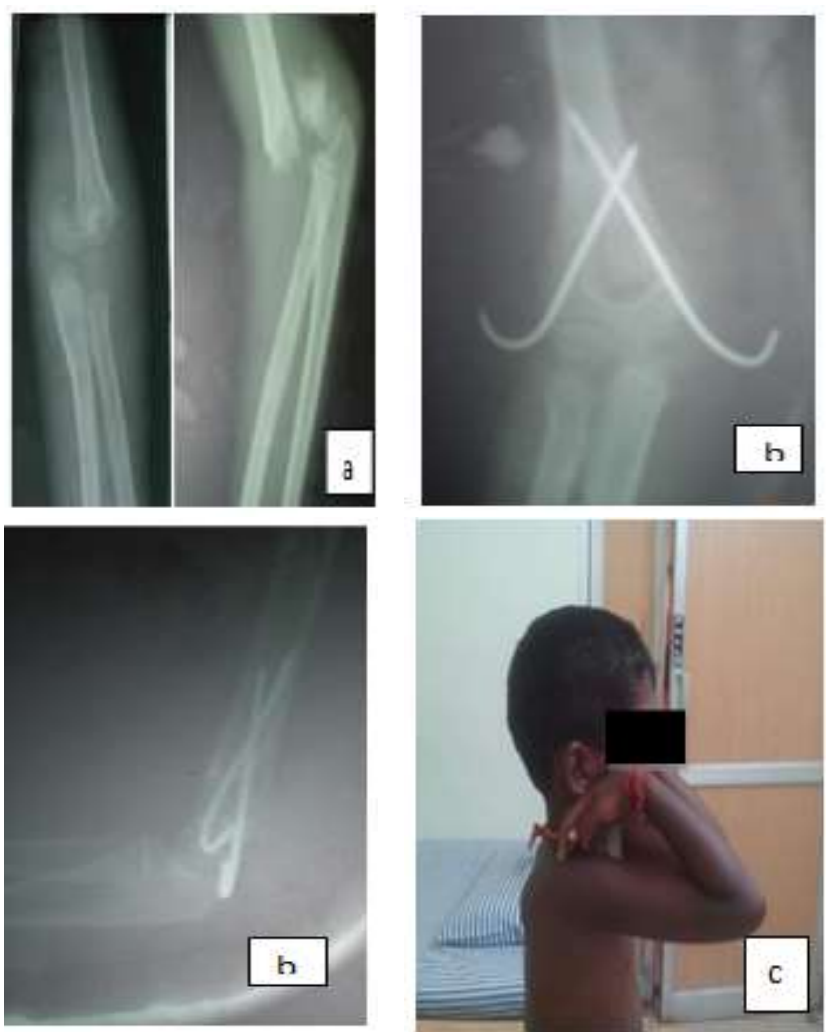

Figure 4: a)pre operative b) post operative radiograph with cross pinning c) 6 month follow up clinical picture with excellent outcome according to flynn's criteria.

Pin tract infection occurred in five children in our study (9\%). The infection was treated with appropriate antibiotics and regular wound dressing. The above elbow slab was continued in these children. Infection was fully eradicated in all with the above measures. There were three cases of IUNI following medial pinning (11\%), in two cases patients had a significant palsy which recovered by three months, one case had only transient paraesthesia. In all cases pin was removed at the end of fourth week.

\section{DISCUSSION}

The aims in the management of the displaced supracondylar fracture are to reduce and immobilize the fracture to reduce its morbidity; CRPP has consistently given good results compared to other methods of treatment. But the controversy persists in literature regarding optimal method of pin fixation. Swenson, Casiano and Flynn et al advocated the use of criss cross pinning. ${ }^{8,10,11}$ Arino and skaggs et al used lateral pins. ${ }^{9,12}$ The goal of all forms of treatment is the same, to obtain and maintain an anatomic reduction of the distal humerus to minimize complications such as nerve injury, compartment syndrome, Volkmann ischaemic contracture, cubitus varus deformity and limitation of elbow movements.

The advantage of using criss-cross pinning is to increase the stability of the fracture fixation thus decreasing the potential for loss of reduction, but simultaneously it carries increased risk of IUNI due to placement of the medial pin. Lateral pin configuration has the advantage of avoiding IUNI, but this construct has been thought to be biomechanically less stable.

In our study, IUNI was $11 \%$. In literature, Arino et al reported that it was almost $21 \%$, ulnar nerve deficit. ${ }^{12}$ In other study it was found in $15 \%$ of patients who were treated with medial and lateral pin as per the report of Chai. $^{13}$

Sankar et al studied the loss of pin fixation in supracondylar fractures. ${ }^{14}$ In all cases, loss of fixation was due to technical errors that were identifiable intraoperative fluroscopic images and that could have been prevented with proper technique. He identified three types of pin-fixation errors: (1) failure to engage both fragments with two pins or more, (2) failure to achieve bicortical fixation with two pins or more, and (3) failure to achieve adequate pin separation $(>2 \mathrm{~mm})$ at the fracture site.

Skaggs et al showed failure of "lateral-entry pin fixation" technique is mainly due to technical errors. He suggested to maximize pin separation at the fracture site, to engage both columns proximal to the fracture, and to engage sufficient bone in both segments. He also suggested surgeons should have low threshold for using the third lateral pin. ${ }^{15}$

From this retrospective analysis, both fixation techniques were good in terms of stability, function and cosmetic outcome. The problem with cross pinning was IUNI due to medial pinning. So lateral pinning is reliably safe method and provides adequate stability in displaced supracondylar fractures.

\section{ACKNOWLEDGEMENTS}

Authors would like to thank all patients for their cooperation in study. We also thank Gnanasundaram R, Tiwari RK for typing the manuscript.

Funding: No funding sources

Conflict of interest: None declared

Ethical approval: Not required 


\section{REFERENCES}

1. Gartland JJ. Management of supracondylar fractures of the humerus in children. Surg Gynecol Obstet. 1959;109(2):145-54.

2. Wilkins KE. Supracondylar fracture of the distal humerus. In: Rockwood CA, Wilkins KE, Beaty JH. (editors) Fractures in Children. $4^{\text {th }}$ ed. Vol 3. Philadelphia, Lippincott-Raven; 1996:669-75.

3. Dunlop J. Transcondylar fractures of the humerus in childhood. J Bone Joint Surg. 1939;21(1):59-73.

4. Worlock PH, Christopher C. Severely displaced supracondylar fractures of humerus in children: A simple method of treatment. J Pediatr Orthop. 1987;7(1);49-53.

5. Smith FM. Kirschner's wire traction in elbow and upper arm injuries. Am J Surg. 1947;74(5):700-87.

6. Mazda K, Boggione C, Fittoussi F, Pemecot GF. Systemic pinning of displaced extension type supracondylar fractures of the humerus in children. J Bone Joint Surg. 2001;83(6):888-93.

7. Brauer CA, Lee BM, Bae DS, Waters PM, Kocher MS. A systematic review of medial and lateral entry pinning versus lateral entry pinning for supracondylar fractures of the humerus. J Pediatr Orthop. 2007;27(2);181-6.

8. Flynn JC, Mathews JG, Benoit RL. Blind pinning of displaced supracondylar fractures of the humerus in children. J Bone Joint Surg Am. 1974;56(2):263-73.

9. Skaggs D, Pershad J. Pediatric elbow trauma. Pediatr Emerg Care. 1997;13(6):425-34.
10. Swenson AL. Treatment of supracondylar fractures of the humerus by Kirschner wire trans-fixation. J Bone Joint Surg Am. 1948;30A(4):993-7.

11. Mazda K, Boggione C, Fittoussi F, Pemecot GF. Systemic pinning of displaced extension type supracondylar fractures of the humerus in children. $\mathrm{J}$ Bone Joint Surg Br. 2001;83(6):888-93.

12. Arino VC, Lluch EE, Ramirez AM et al. Percutaneous fixation of supracondylar fractures of the humerus in children. J Bone Joint Surg Am. 1997;59(7):914.

13. Chai KK. A prospective study on supracondylar fracture of the humerus in children: comparing the results of closed manipulation and plaster cast with closed manipulation and percutaneous cross $\mathrm{K}$ farctures. Master Thesis: University of Malaya;2000.

14. Sankar WN, Hebela NM, Skaggs DL, Flynn JM. Loss of pin fixation in displaced supracondylar humeral fractures in children: causes and prevention. J Bone Joint Surg. 2007;89(4):713-7.

15. Skaggs DL, Hale JM, Bassett J, Kaminsky C, Kay RM, Tolo VT. Operative treatment of supracondylar fractures of the humerus in children. The consequences of pin placement. J Bone Joint Surg Am. 2001;83-A(5):735-40.

Cite this article as: Govindasamy $\mathrm{R}$, Gnanasundaram R, Kasirajan S, Thonikadavath F, Tiwari RK. Cross pinning versus lateral pinning in type III supracondylar fracture: a retrospective analysis. Int J Res Orthop 2016;2:138-42. 